\title{
Mathematical Models and Effectiveness Analysis of Government Educa- tion and Health Expenditures on Economic Growth
}

\author{
Xiaoping Huang ${ }^{1}$, Lixiang Tang ${ }^{2, *}$, Yang Peng ${ }^{3}$ and Ziwei Xiao ${ }^{4}$ \\ ${ }^{1}$ Business School, Hunan Normal University, Hunan410081, China; ${ }^{2}$ Department of Business Administration, Hunan \\ Finance and Economics University, Hunan410205, China; ${ }^{3}$ Department of Business Administration, Hunan University \\ of Finance and Economics, Hunan410205, China: ${ }^{4}$ Business School, Hunan Normal University, Hunan410081, China,
}

\begin{abstract}
This paper establishes a novel mathematical model to analyze the effects of government education and health expenditures on the economic growth. Based on the Cobb-Douglas production function, the analysis of education and health expenditures is conducted using the two-stage least square method and applying the Gaussian mixture model as the estimation method. The results provide not only the long-term relationship between education and economic growth, but also between health expenditure and economic growth. In addition, they show that both education and health expenditures have different contributions to economic growth, resulting in unbalanced development in various districts. We also compare the per capita public health and education expenditures and their economic effects in different regions. We conclude that the district with relatively less contribution may not necessarily increase their expenditure; hence, effective management may be more important. In accordance with the regional contribution divergence, the government should formulate corresponding policies to improve the allocation of education and health resources and ensure rational capital flow among regions.
\end{abstract}

Keywords: Cobb-douglas production function, empirical analysis, government education and health expenditures, mathematical model.

\section{INTRODUCTION}

With the economic development of a country, an increasing tendency emerges to place greater value on the quality of life among its people. This emphasis places a higher demand for medical and educational services. Many studies shown that government expenditures, especially in health and education sectors, could bring positive effects on human capital, at the end, boost economic growth while promoting equity and reducing poverty. Previous empirical studies have found that health and education expenditures widely vary in different countries. Educational expenditure has a pivotal role in enhancing the quality of human capital, improving people's health, and promoting coordinated growth of the regional economy. In China, educational expenditure can also promote economic development to some extent. However, it presents an obvious regional discrepancy, that is, educational expenditures in different regions have different roles when it contributes to economic growth. When analyzing the relationship between health expenditure and economic growth (measured by fiscal health spending), in most studies, the authors regard "the insufficient fiscal health expenditure scale" as one of the main difficulties in the health care reform in China. Ping (2003) thinks that fiscal expenditure on public health accounting for total health expenditure in
China is the lowest in the world, and farmers' public health expenditure which accounts for $80 \%$ of the population is in the proportion of less than $20 \%$ [1]. Through the comparative analysis between China and other countries, Chen (2009) finds that the structure of fiscal expenditure of public health in our country is unreasonable by level of government, and the reason for this owns to the imperfect system [2]. However, with the development of social economy, the Government has also increased health input. Although the growth rate of health spending has exceeded the GDP rate, relevant issues ("poor access and high fees" and "being into poverty by illness") remain in China. These situations cause public uncertainty on whether the inputs of health expenditure and the consumption of health resources are too much. Moreover, questions on whether these conditions can be attributed to unreasonable distribution of expenditure and whether the waste of resources comes from the ignorance of regional difference have also emerged. Thus, the aim of this paper is to conduct an analysis to help the Government determine the scale of educational and health expenditures as well as weigh the rationality of resource allocation in different regions, so that it can comes up with appropriate policies to guide the distribution of resources.

The rest of this paper as follows: In section 2,we review the related theory about the effects of government education and health expenditures on economic growth; In section 3, we conduct the empirical research using the panel data of the provinces in China; and section 4 provides the policy recommendations and conclusion. 


\section{LITERATURE REVIEW}

In 1987, Schultz conducted a quantitative analysis of the relationship between education expenditure and economic growth of the United States from 1929 to 1957, demonstrating a $17 \%$ average yield of educational expenditure, which accounts for $33 \%$ of the national income growth [3]. Based on the Overlapping Generation Model, Docquier and Paddiso (2003) and Cruz (2006) selected the decision according to the life-long maximum utility of individuals, in order to illustrate the process of investing in education and how these investments influence economic growth [4,5]. Blankenau (2004) analysed the effect mechanism of education expenditure on economic growth based on the two-sector growth model and pointed out that education expenditure can foster the development of an economy [6]. Kleiman and Newhouse conducted separate pioneering studies on the effects of health expenditure. They both hold the view that a strong positive correlation exists between National Health Expenditure (NHE) and GDP, and that per capita NHE is mainly decided by per capita GNP or per capita income [7, 8]. Through further analysis of 13 developed countries, Newhouse believes that the elasticity of health care expenditure is greater than that of income [8].

In the 1990s, Hansen and King and Blomqvist and Cater, among others, used the time-series model in their studies and stressed the stability of NHE and GDP to avoid spurious regression $[9,10]$. However, with the panel data model becoming more mature, especially with the proposal of a dynamic panel, many scholars have conducted studies based on the panel data model. Panel data analyses eliminate the influence of multicollinearity in the time-series model as well as enhance the flexibility and estimated efficiency. Rivera and Currais analysed the rates of per capita GDP and NHE using the panel data of 24 OECD countries from 1960 to 1990 , and reported that per capita GDP increased by $2.1 \%$ to $2.2 \%$ for every $1 \%$ increase in health expenditure [11]. In another study, they analyzed 17 regions of Spain from 1973 to 1993 , and demonstrated that per capita GDP increased by $0.16 \%$ for every $1 \%$ increase in health expenditure [12]. Recently, the existence of coordination and causality between NHE and GDP has also become a hot topic among foreign scholars. For example, Gerdtham and Lothgren demonstrated a long and stable relationship between NHE and GDP using the panel co-integration test [13]. Clementa et al. obtained the same result in their study [14]. Bloom and Canning also explained this relationship, in which, an increase in NHE can lead to an increase in the insurance and wealth of workers; in turn, these enhanced labour efficiency and promoted economic growth [15]. Tan (2005) reported that the increase in health expenditure in China can affect the whole nation's health condition and enhance the fitness level of its population, thus it can create an external environment for increasing national economy and social fortune [16]. Geng (2008) demonstrates that public health expenditure has higher elastic coefficient and contribution rate-even higher than that of human capital; however, the long-term economy shows less growth, which is not accompanied by public health spending [17]. Other studies have focused on the relationship between economic growth and fiscal health expenditure. However, only a few of these have been reported, especially the analy- sis based on modern statistical tools. In 2004, Wang conducted an empirical study on this relationship using data from 1993 to 1999, which divided China into the East, the Middle, and the West. He pointed out that the contributions of per capita public health expenditure on per capita GDP are $0.21,0.13$ and 0.96 , respectively, showing the apparent characteristics of various stages in the regional economic growth, namely, high-low-high trend [18].

Based on the above review, scholars have carried out some sound explorations on the effects of education and health expenditures on economic growth. However, when using panel data analysis, the research between countries is more than that of different regions within a country. Different countries have different systems; thus, the research results cannot be reliable. About the studies of China, the relationship between education and health expenditures and GDP are dealt with direct linear regression analysis. However, this kind of analysis lacks the stability test of data and produces bias for missing important explanatory variables. Therefore, we need to reestablish an economic growth model of education and health expenditures based on the analysis of the effects among provinces, with emphasis on the growth factor.

\section{MODEL CONSTRUCTION}

The Neoclassic Production Growth model, in which capital and labor are constant returns to scale, attempts to explain long-term economic growth by looking at capital accumulation, labor or population growth, and technological progress as exogenous observables. Scholars after it have added human capital as a factor of production in the Solow-Swan model. When the measurement was taken on human capital, only the index of education was used and the index of health was excluded. However, without workers who are equipped with the basic level of education and health, the economy cannot achieve a long-term growth. Thus, the economic growth model should also consider the factors of education and health. We adopt the Cobb-Douglas production function and added the economic growth model of fiscal health expenditure as follows:

$$
Y_{i t}=K_{i t}^{\alpha}\left(E_{i t}^{\beta} H_{i t}^{\gamma}\right)\left(A_{i t} L_{i t}\right)^{\mu} \quad \mu=1-\alpha-\beta-\gamma,
$$

where $Y_{i t}, E_{i t}, H_{i t}, A_{i t}$, and $L_{i t}$ represent the total output, physical capital, educational expenditure, fiscal health expenditure, and technological level and labour forces in time $t$ at region $i$, respectively, and $\alpha$ ! $\beta \quad \gamma \quad \mu$ symbolize the corresponding variable elasticity. We assume that the growth rate of $L$ and $A$ are exogenous factors and are already given as $g$ and $n$, respectively. These variables meet the conditions given by $L(t)=L(0) e^{n t}$ and $A(t)=A(0) e^{g t}$. In addition, all the variables are assumed to have the same production function and depreciation. After a set of mathematical deductions, the model can be obtained as follows:

$$
\begin{aligned}
& \ln \left(\hat{y}_{i t}^{*}\right)=\frac{\alpha}{\mu} \ln \left(s_{k_{i t}}\right)+\frac{\beta}{\mu} \ln \left(s_{e_{i t}}\right)+\frac{\eta}{\mu} \ln \left(s_{h_{i t}}\right)-\frac{1-\mu}{\mu} \ln \\
& \left(n_{i t}+g_{i t}+\delta_{i t}\right)+v_{i t}+u_{i t} .
\end{aligned}
$$


Chart 1. Metric method and source of variables.

\begin{tabular}{|c|c|c|}
\hline Variables & Metrics & Data Sources \\
\hline \hline$\hat{y}^{*}$ & Practitioners' real per capita GDP in constant prices of 1978 & $\begin{array}{c}\text { Statistical Yearbook from 2001 to 2011 } \\
\text { Total amount of fixed assets/GDP }\end{array}$ \\
\hline$s_{k}$ & Fiscal education expenditure/GDP & $\begin{array}{c}\text { GDP from 2005 to 2008 was revised after the second eco- } \\
\text { nomic census }\end{array}$ \\
\cline { 1 - 2 }$s_{e}$ & Fiscal health expenditure/GDP & China Health Statistical Yearbook from 1999 to 2010 \\
\hline$n$ & Population growth rate & Statistical Yearbook from 2001 to 2011 \\
\hline$g+\delta$ & 0.05 as the approximate estimation & \\
\hline
\end{tabular}

For further consideration, we bring in the one-step-delay variables as explaining variables to avoid missing the important variables, which can lead to estimation bias. The dynamic panel data regression model is presented as follows:

$$
\begin{aligned}
& \ln \left(\hat{y}_{i t}^{*}\right)=\theta \ln \left(\hat{y}_{i, t-1}^{*}\right)+\frac{\alpha}{\mu} \ln \left(s_{k_{i t}}\right)+\frac{\beta}{\mu} \ln \left(s_{e_{i t}}\right)+\frac{\gamma}{\mu} \ln \left(s_{h_{i t}}\right) \\
& -\frac{1-\mu}{\mu} \ln \left(n_{i t}+g_{i t}+\delta_{i t}\right)+v_{i t}+u_{i t} \\
& (i=1,2 \cdots 31, \quad t=1,2 \cdots 10),
\end{aligned}
$$

where $\hat{y}_{i t}{ }^{*}$ stands for the per capita GDP of $i$ province at year $t ; s_{k_{i t}}, s_{e_{i t}}$, and $s_{h_{i t}}$ represent the physical capital, educational expenditure, and rate of fiscal health expenditure, respectively; and $g_{i t}, n_{i t}$, and $\delta_{i t}$ are the growth rates of technology, workforce and depreciation, respectively.

\section{DATA ANALYSIS}

Data were obtained from 31 provinces, autonomous regions, and municipalities in China from 2001 to 2011. The metrics of each variable are shown in Chart 1.

In the Statistical Yearbook of China in 2007, the number of employment population default in 2006 and the data of each Provincial Statistical Yearbook are inconsistent with the China Statistical Yearbook. In addition, the 2006 data cannot be replaced by the data from the Provincial Statistical Yearbook in 2007. Therefore, we used the average employment data of 2005 and 2007 to replace these data.

A: Panel Unit Root Test. Considering the time trend and spurious regression among the data, panel unit root test and co-integration test was conducted for the variables, after which we ran a regression analysis to achieve sensible regression results. Through the analysis of the evolutionary process of unbalanced panel data, scholars have found that the estimator of the limiting distribution is Gauss distribution. These results are also commonly applied on panel data with heteroscedasticity to establish an early version of the panel unit root test. Recently, the LLC method of unit root test is proposed to improve these test results. The test results of the ADF-Fisher unit root and they are listed (See chart 2) in this paper. When these two kinds of tests reject the null hypothesis, the series are stable, otherwise the series are unstable.

Chart 2 shows that the statistics of ADF-Fisher and LLC of the $\ln \hat{y}^{*}, \ln \hat{y}^{*}(-1), \ln s_{k}, \ln s_{e}$ and $\ln s_{h}$ sequences are larger than the critical value; however, after the first order difference, they all rejected the existence of the unit root. Thus, the test results show that $\ln \hat{y}^{*}, \ln \hat{y}^{*}(-1), \ln s_{k}, \ln s_{e}$, and $\ln s_{h}$ are integrated to order 1 . The result of the LLC test for the $\ln (n+g+\delta)$ sequence shows that it rejected the null hypothesis. However, the statistical result of the ADF-Fisher exhibited the opposite, that is, after the first order difference, the sequence became stationary. Thus, $\ln (n+g+\delta)$ is integrated to order1.

B: Panel co-integration Test. The results of the panel unit root test show that all the sequences are integrated to order 1 and meet the necessary conditions for the co-integration equation. Thus, we continue the co-integration test of the panel data. Considering stability, the Pedroni test based on the panel co-integration residual error was used under the condition that the null hypothesis had no co-integration in dynamic multivariate regression. The results of the Kao test using the extended test of DF and ADF are also listed (see Chart 3).

According to the proof of Pedroni, the effects of panel ADF-Statistic, Group ADF-Statistic are better in small samples, while the Panel v-Statistic has fewer effects. From the estimated values in Chart $\mathbf{3}$, the Pedroni's panel ADFStatistic, panel PP-Statistic, Group ADF-Statistic, and the test result of Kao's ADF value all reject the null hypothesis, which is not co-integrated at a $1 \%$ significant level, thus supporting the long existence of integration.

C: Long-term Equation Estimation. To explore the impacts of fiscal health expenditure on economic growth, we conduct an empirical analysis on the theoretical model. In the model, the explained variables and explaining variables have interactive relationships. The explained variables of dynamic interconnected terms and the random variables may also have a relationship. To avoid these hindrances and to strengthen the stability of the model, we adopted the fixedeffects model with AR (P) (GLS), two-stage least squares method (TSLS), and Gaussian Mixture Model (GMM) to estimate the theoretical model (see Chart 4). 
Chart 2. Panel unit root test for variables.

\begin{tabular}{|c|c|c|c|c|}
\hline Variables Sequences & Test form $(C, T)$ & Statistics of ADF-Fisher & Statistics of LLC & Results \\
\hline $\ln \hat{y}^{*}$ & $(\mathrm{C}, \mathrm{N})$ & $51.77(0.82)$ & $-1.13(0.23)$ & $\mathrm{I}(1)$ \\
\hline$\Delta \ln \hat{y}^{*}$ & $(\mathrm{C}, \mathrm{N})$ & $200.80(0.00)$ & $-17.12(0.00)$ & $\mathrm{I}(0)$ \\
\hline $\ln \hat{y}^{*}(-1)$ & $(\mathrm{C}, \mathrm{N})$ & $46.77(0.92)$ & $2.67(0.99)$ & $\mathrm{I}(1)$ \\
\hline$\Delta \ln \hat{y}^{*}(-1)$ & $(\mathrm{C}, \mathrm{N})$ & $159.06(0.00)$ & $-15.35(0.00)$ & $\mathrm{I}(0)$ \\
\hline $\ln s_{k}$ & $(\mathrm{C}, \mathrm{N})$ & $26.30(1.00)$ & $5.33(1.00)$ & $\mathrm{I}(1)$ \\
\hline$\Delta \ln s_{k}$ & $(\mathrm{C}, \mathrm{N})$ & $98.52(0.002)$ & $-5.91(0.00)$ & $\mathrm{I}(0)$ \\
\hline $\ln s_{e}$ & $(\mathrm{C}, \mathrm{N})$ & $41.93(0.98)$ & $-0.61(0.27)$ & $\mathrm{I}(1)$ \\
\hline$\Delta \ln s_{e}$ & $(\mathrm{C}, \mathrm{T})$ & $115.57(0.00)$ & $-16.56(0.00)$ & $\mathrm{I}(0)$ \\
\hline $\ln s_{h}$ & $(\mathrm{C}, \mathrm{T})$ & $27.92(0.99)$ & $2.07(0.98)$ & $\mathrm{I}(1)$ \\
\hline$\Delta \ln s_{h}$ & $(\mathrm{C}, \mathrm{T})$ & $111.50(0.00)$ & $-11.56(0.00)$ & $\mathrm{I}(0)$ \\
\hline $\ln (n+g+\delta)$ & $(\mathrm{N}, \mathrm{N})$ & $73.94(0.14)$ & $-4.23(0.00)$ & $\mathrm{I}(1)$ \\
\hline$\Delta \ln (n+g+\delta)$ & $(\mathrm{C}, \mathrm{N})$ & $241.68(0.00)$ & $-16.69(0.00)$ & $\mathrm{I}(0)$ \\
\hline
\end{tabular}

Note: $(\mathrm{C}, \mathrm{T})$ represents the test form, where $\mathrm{C}$ means having constant terms and $\mathrm{T}$ means having time trend. The values in the brackets correspond to a $\mathrm{P}$ value.

Chart 3. Test for co-integration.

\begin{tabular}{|c|c|c|}
\hline \multicolumn{1}{|c|}{} & Statistics \\
\hline \hline \multirow{4}{*}{$\begin{array}{c}\text { Pedroni } \\
\text { Test }\end{array}$} & Panel v-Statistic & -3.205854 \\
\cline { 2 - 3 } & Panel rho-Statistic & 3.698949 \\
\cline { 2 - 3 } & panel PP-Statistic & $-18.23064 * * *$ \\
\cline { 2 - 3 } & panel ADF-Statistic & $-9.532062^{* * *}$ \\
\cline { 2 - 3 } & Panel v-Statistic & 7.063848 \\
\cline { 2 - 3 } & Group PP-Statistic & $-20.56568 * * *$ \\
\hline Kao Test & Group ADF-Statistic & $-8.921350^{* * *}$ \\
\hline
\end{tabular}

Note: $* * *$, and $* * *$ show that they are greatly related with $0.1,0.05$ and 0.001 , respectively.

Based on the regression results, the general model is significant and has high coefficient of determination, regardless of the kind of method used in the regression. From the aspect of each influencing factors, most of the variables can pass the significance test and stay at high levels. We also find that there are different coefficients before each variable for different methods, which may be due to the different selection of instrumental variables. However, the effect trend of the dependent variable is consistent. GMM can solve the endogenous problems and individual effects. Therefore, we can use the GMM regression results to analyse the impact of investment in education and health on economic growth.

Investments related to health are included in fiscal health expenditures, and can produce a certain positive effect on economic growth. When the other condition is kept constant, the economic growth increases by $0.148 \%$ for every $1 \%$ addition to health expenditure. Meanwhile, education expenditure also promotes economic growth. Its influence coefficient is 0.2886 , that is, each $1 \%$ increase in education expenditure leads to a $0.2886 \%$ increase in economic growth Compared with other estimates, which only analyse the impacts of education human capital to economic growth, the elastic value is lower in domestic studies. The results of previous research show that the elastic value ranges between 0.46 and 0.55 , indicating that health human capital has a role in economic growth.

To further analyse the effects of education and health expenditure on economic growth as well as to weigh the rationality of resource allocation in different regions in the theoretical model, we assume that the effects varied in different regions (i.e., different regions obtained different values of $\ln s_{e}$ and $\ln s_{h}$ ). In the estimations of $\ln s_{e}$ and $\ln s_{h}$ based on varying-coefficient models, in which other variables are regarded as control variables, the coefficients of dependent control variables showed few differences with those in Chart 4. Therefore, only the coefficients before $\ln s_{e}$ and $\ln s_{h}$ are listed (see Chart 5).

Chart 5 shows that education and health expenditures have different contributions to economic growth, leading to unbalanced development in different regions. In such provinces as Xinjiang, Jilin and Hubei, both expenditures have greater contribution, indicating that the scales of expenditure are at reasonable levels or the marginal revenues remain at a high level. However, the lower contribution areas, such as Qinghai, Tianjin and Inner Mongolia, do not represent the need of increasing investment. The lower contributions may 
Chart 4. Estimation results.

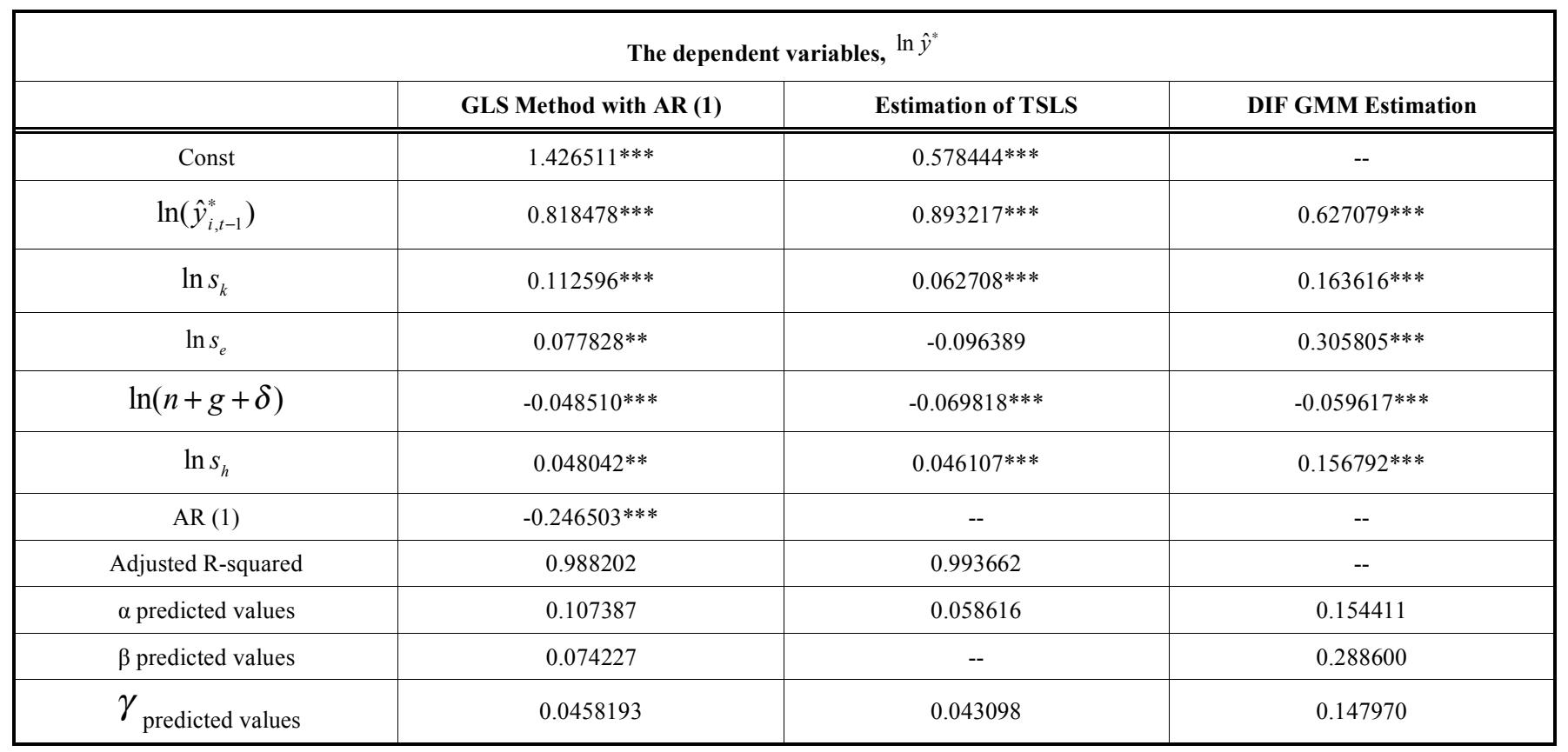

Note: $*, * *,{ }^{* * *}$ show that they are greatly related with $0.1,0.05$ and 0.001 , respectively.

Chart 5. Coefficients of the influence of education and health expenditures of different regions on provincial economic growth.

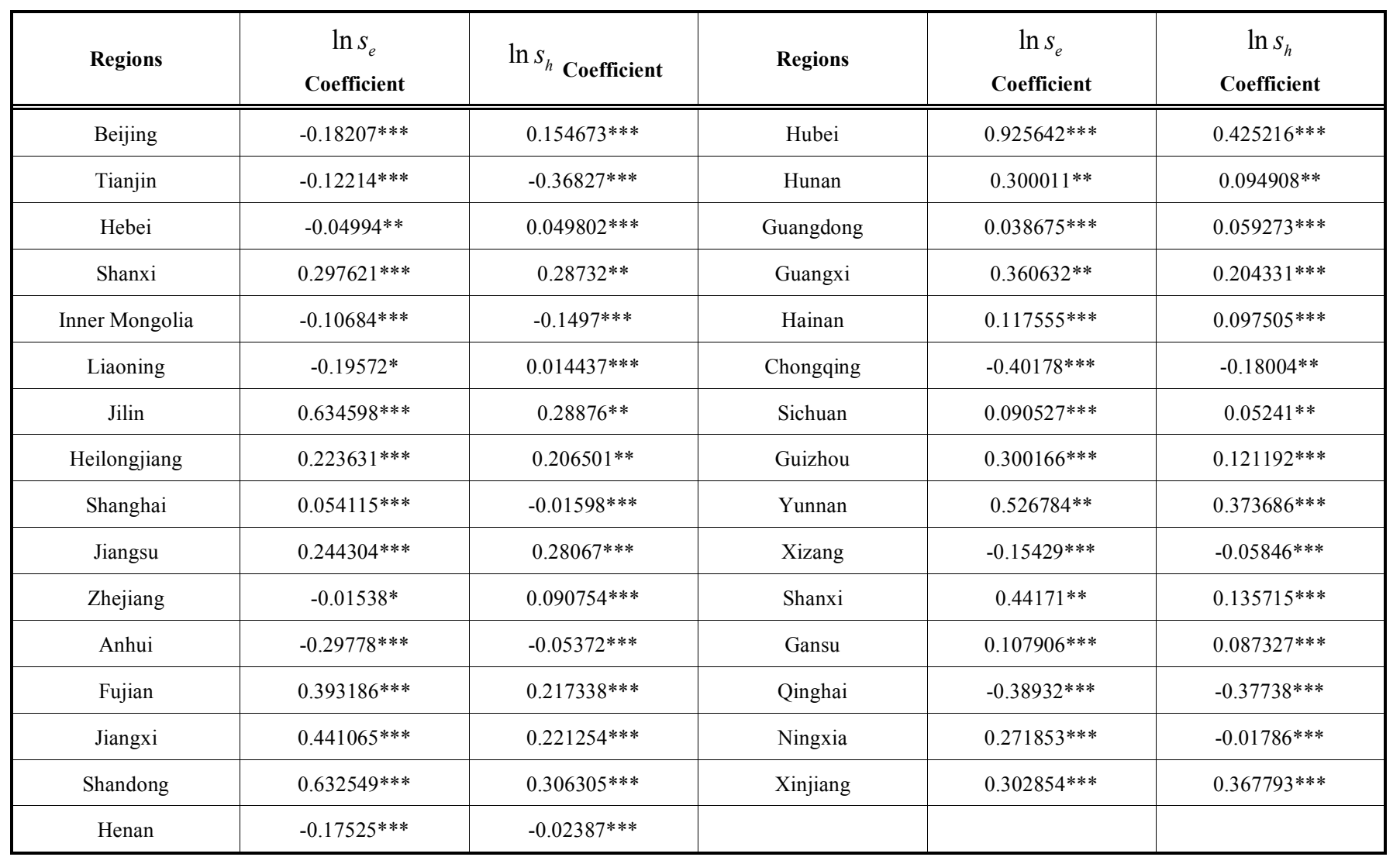

Note: $*, * *, * * *$ show that they are greatly related with $0.1,0.05$ and 0.001 , respectively.

be due to the relatively high local expenditure, which crowd out corresponding physical capital accumulation. Therefore, the categories of Chart 6 are classified based on the values of contribution and fiscal health expenditures among provinces. We then analyze the scales and effects of education and health investment in various provinces (Chart 6). 
Chart 6. Classifications of the effects of education and health expenditures on economic growth among different regions.

\begin{tabular}{|c|c|c|c|c|c|c|}
\hline & \multicolumn{5}{|c|}{ Ranking of Provinces per Capita Educational Expenditure } \\
\hline \hline $\begin{array}{c}\text { Greatest effect on } \\
\text { economic growth } \\
\text { (Top 10) }\end{array}$ & Yunnan, Xinjiang 10 & $\begin{array}{c}\text { Jilin, Shanxi, Ji- } \\
\text { angsu, Fujian, } \\
\text { Heilongjiang }\end{array}$ & $\begin{array}{c}\text { Hubei, Shandong } \\
\text { Jiangxi }\end{array}$ & Xinjiang & $\begin{array}{c}\mathbf{1 1}^{\text {th }}-\mathbf{3 1}^{\text {th }} \\
\text { Jilin, Yunnan, } \\
\text { Shaanxi, Fujian }\end{array}$ & $\begin{array}{c}\text { Hubei, Shandong, } \\
\text { Jiangxi, Guangxi, } \\
\text { Guizhou }\end{array}$ \\
\hline $\begin{array}{c}\text { General effect } \\
\text { on economic } \\
\text { growth } \\
\text { (ranking 11-20) }\end{array}$ & Beijing, Zhejiang & $\begin{array}{c}\text { Shaanxi, Hainan, } \\
\text { Gansu, Guangdong }\end{array}$ & $\begin{array}{c}\text { Guangxi, Guizhou, } \\
\text { Hunan, Sichuan }\end{array}$ & $\begin{array}{c}\text { Ningxia, Shanghai, } \\
\text { Guangdong }\end{array}$ & $\begin{array}{c}\text { Shanxi, Jiangsu, } \\
\text { Heilongjiang, } \\
\text { Hainan, Gansu, }\end{array}$ & Hunan, Sichuan, \\
\hline $\begin{array}{c}\text { Less effect } \\
\text { or restraint on } \\
\text { economic growth } \\
\text { (ranking 21-31) }\end{array}$ & $\begin{array}{c}\text { Tibet, Shanghai, } \\
\text { Ninghai, Tianjin, } \\
\text { Mongolia }\end{array}$ & Liaoning & $\begin{array}{c}\text { Hebei, Chongqing, } \\
\text { Anhui, Henan }\end{array}$ & $\begin{array}{c}\text { Mongolia, Tianjin, } \\
\text { Tibet, Beijing, } \\
\text { Qinghai }\end{array}$ & Liaoning \\
\hline
\end{tabular}

Note: The rankings of the per capita fiscal health and education expenditures were obtained from the average values from 2001 to 2010.

Chart 6 shows that the expenditures in Hebei, Chongqing, Anhui and Henan provinces have fewer effects on economic growth and that the government inputs are lower than those in other provinces. Low education and health expenditures may not provide a healthy workforce and help the citizens adapt to modernized production processes. Such inadequacy can influence the long-term economic development of these provinces. Moreover, the slow economic growth reduces the government's ability to initiate further development, thus producing a vicious cycle. Therefore, these provinces should increase expenditures in education and health to maintain long-term economic development.

Second, although the expenditures in Tibet, Qinghai, Tianjin and Inner Mongolia provinces are high, their contributions to economic growth remain low. Insufficient investment is no longer the bottleneck that restricts education as well as health care reform and economic development in these provinces. In fact, their higher contributions may disregard other public investments and physical capital accumulation, which can lead to wasted social health resources and stifled economic growth.

Finally, health and education expenditures in Hubei, Shanxi, Jiangxi, Guangxi and Guizhou provinces are lower, but their contributions to economic growth are greater, indicating large regional differences with the same scales of investment in economic growth. Thus, these provinces should reasonably allocate resources according to local conditions.

\section{CONCLUSIONS AND POLICY RECOMMENDA- TIONS}

In this work, we conducted an empirical study on the effects of government education and health expenditures on economic growth among provinces in China. We used panel data of 31 provinces from 2001 to 2011 . Based on the CobbDouglas production function, an economic growth model was established, in which education and health expenditures were added. This model used estimation methods, including TSLS and GMM. The main conclusions are summarized below.
(1) Education and health expenditures have important roles in promoting the economy. Although current education and health expenditures are increasing, they do not reflect public doubts about the excessive consumption of education and health resources. The fiscal health expenditure does not disregard other public investments and physical capital accumulation, or the effect is not enough to promote economic growth. At the same time, health expenditure is a pure consumptive expenditure of the government and individuals that has investment-profit orientation. Therefore, regional governments should provide significant attention to the expenditure of health.

(2) The contributions of education and health expenditures to economic growth vary in different regions in China. The contributions in Xinjiang, Jilin, Hubei, Fujian and Jiangxi provinces are greater, whereas the contributions in Tibet, Qinghai, Tianjin, Inner Mongolia, Liaoning, Hebei, Henan, Anhui and other provinces are relatively low. On the one hand, the region with small scale expenditures on education and health and smaller contributions to economic growth are able to strengthen their expenditures. On the other hand, the regions with higher economic growth rates have reasonable levels of education and health expenditure scales, that is, the fiscal health expenditures are at the stage of higher marginal revenues.

(3) Lower contribution to economic growth does not mean that the government must increase its education and health expenditures; in such case, effective management should be an important issue to consider. Tibet, Qinghai, Tianjin, Inner Mongolia, and other provinces have high education and health expenditures, but their contributions to economic growth are small. Therefore, for these provinces, insufficient investments no longer comprise the bottleneck that restricts education as well as health care reform and economic development. In fact, such higher contributions may disregard other public investments and physical capital accumulation that, in turn, may lead to wasted social health resources and stifled economic growth. 
(4) Based on the regional difference effects of education and health expenditures, policies must be created to improve the quality of expenditures among regions and the capability to allocate health resources and guide rational capital flow between regions. In provinces with insufficient expenditures, priority should be given to increase their scales as well as the marginal effect of education and health expenditures. Meanwhile, in the provinces with sufficient investments, effective management should be conducted to enable them to lead insufficient provinces and guide capital flow between regions.

\section{CONFLICT OF INTEREST}

The authors confirm that this article content has no conflict of interest.

\section{ACKNOWLEDGEMENTS}

This work was financially supported by the the Hunan Provincial Finance Department in China, entitled, "Research on the Regional Fairness of Public Health Expenditure in China"and NSFC(No.11171079).

\section{REFERENCES}

[1] X. Q. Ping, "The choice of financing mechanism of the medical care in rural areas through farmers' behaviors in care spending," Management World, vol. 11, pp.52-63, 2003.

[2] C. C. Chen, and J. L. Zhou, "Analysis of intergovernmental burden structure of public health expenditure in China," China Health Economics, vol.8, pp. 62-70, 2009.

[3] G. S. Becker, " Human capital," Beijing, Peking University Press, vol. 1, pp.168, 1987.

[4] D. Frederic, and O. Paddison, "Social security benefit rules, growth and inequality," Journal of Macroeconomics, vol. 25, pp. 47-71, 2003.
[5] E. A. Cruz, and Lza, "Life expectancy, human capital, social security and growth," Journal of Public Economics, pp. 2323-2349, 2006.

[6] W. F. Blankenau, and N. B. Simpson, "Public education expenditures and growth," Journal of Development Economics, vol. 73 , pp.583-605, 2004.

[7] E. Kleiman, "The determinants of national quantity on health," The Economics of Health and Medical Care, vol. 10, pp. 369-376, 1974.

[8] Newhouse, "Medical care expenditures: a cross-national survey," Journal of Human Resources, vol. 12, pp. 115-125, 1977.

[9] P. Hansen, and A. King, "Health care expenditure and GDP: panel data unit root test results-comment," Journal of Health Economics, vol. 17, pp. 127-137, 1998 .

[10] A. G. Blomqvist, and R. A. L. Carter, "Is health care really a luxury?," Journal of Health Economics, vol. 16, 207-229, 1997.

[11] B. Rivera, and L. Currais, "Income variation and health expenditure: evidence for OECD countries," Review of Development Economies, vol. 3, vol. 258-267, 1999.

[12] B. Rivera, and L. Currais, "Public health capital productivity in the Spanish regions: a dynamic panel data model," World Development, vol. 32, pp. 871-885, 2004

[13] U.G. Gerdtham, and M. Lothgren, "On stationarity and cointegration of international health expenditure and GDP, Journal of Health Economics, vol. 19, pp. 461-475, 2000.

[14] J. Clemente, C. Marcuello, A. Montanés and F. Pueyo, "On the international stability of health care expenditure functions: Are government and private functions similar?," Journal of Health Economics, no.23, pp. 589-613, 2004

[15] Bloom, and D.E. Canning, "Health and economic growth: reconciling the micro and macro evidence," CDDRL Working Papers, 2005

[16] Y. S. Tan, "Structural problems of China's total health expenses and its influence on economic growth," Health Economics Research, vol. 6, pp. 9-11, 2005.

[17] J. H. Geng, and J. F. Miao, "Economic growth effect of public health spending," Social Science Research, vol. 5, pp. 59-62, 2008.

[18] Y. L. Wang, and X.G. Song, "An empirical study of public health investment and regional economic growth," Economists, vol. 2, pp. $51-56,2004$.

(C) Huang et al.; Licensee Bentham Open.

This is an open access article licensed under the terms of the Creative Commons Attribution Non-Commercial License (http://creativecommons.org/licenses/by-nc/3.0/) which permits unrestricted, non-commercial use, distribution and reproduction in any medium, provided the work is properly cited. 